\title{
RESPON SISWA SMA N 1 KOTA BENGKULU TERHADAP LKPD MODEL APOS DENGAN PENDEKATAN SAINTIFIK
}

\section{RESPONSE OF SMA N 1 BENGKULU CITY STUDENTS ON LKPD APOS MODEL WITH SCIENTIFIC APPROACH}

\author{
Oleh: \\ Hanifah $^{1),}$ Nur Aliyyah Irsal ${ }^{2)}$, Nirwana ${ }^{3)}$ \\ Program Studi S2 Pendidikan Matematika ${ }^{1,3)}$ \\ Program Studi S1 Pendidikan Matematika ${ }^{2)}$ \\ FKIP Universitas Bengkulu \\ Email: hanifah@unib.ac.id
}

\begin{abstract}
This service activity aims to train Mathematics and Natural Sciences teachers at SMAN 1 Kota Bengkulu to make their own worksheet based on the APOS Model with a scientific approach, and receive a positive response from students when applying the worksheet in their class. The success indicator of this activity is the creation of worksheets made by teachers which receive positive responses from students. The mathematics teacher group managed to design a Dilatation worksheet with Geogebra software and statistics worksheet with MS Excel. Statistics worksheet that can be applied according to the schedule in class XII IPA 1 in SMA N 1 Kota Bengkulu, attended by 31 students. From the results of a survey collected through an open questionnaire, information was obtained that: $67.74 \%$ of students like to learn using the APOS-based with MS Excel-assisted and scientific approach worksheet; $77.42 \%$ of students like to study in groups; $83.87 \%$ understand the material. Based on the results of observations, students look enthusiastic and active during learning. It can be concluded that the APOS Model with scientific approach worksheets made by SMAN 1 teachers in Bengkulu City received a positive response from students.
\end{abstract}

Keywords: APOS Mode, Saintifik approach, worksheet

\section{PENDAHULUAN}

Proses pembelajaran pada Kurikulum 2013 di sekolah dilaksanakan menggunakan pendekatan ilmiah. Proses pembelajaran menyentuh tiga ranah, yaitu sikap, pengetahuan, dan keterampilan. Dalam proses pembelajaran berbasis pendekatan ilmiah, ranah sikap menggamit transformasi substansi atau materi ajar agar peserta didik "tahu mengapa" Ranah keterampilan menggamit transformasi substansi atau materi ajar agar peserta didik "tahu bagaimana". Ranah pengetahuan menggamit transformasi substansi atau materi ajar agar peserta didik " tahu apa ". Hasil akhirnya adalah peningkatan dan keseimbangan antara kemampuan untuk menjadi manusia yang baik (soft skill) dan manusia yang memiliki kecakapan dan pengetahuan untuk hidup secara layak (hard skills) dari peserta 
didik yang meliputi aspek kompetensi sikap, keterampilan, dan pengetahuan (Daryanto, 2014).

Tujuan kurikulum negara kita tersebut nampaknya masih belum tercapai, terkhusus dalam pelajaran matematika dan IPA. Aspek kompetensi sikap, keterampilan, dan pengetahuan siswa masih tergolong rendah. Untuk pelajaran yang dianggap sulit ini, siswa masih banyak menunjukkan sikap dan respon negatif dalam pembelajarannya sehingga juga berdampak pada kurangnya pencapaian keterampilan dan pengetahuan matematika mereka. Hal ini mengakibatkan mata pelajaran matematika sering kali menjadi penyebab tidak lulusnya seorang siswa dalam ujian nasional. Masalah tersebut masih sering dialami oleh SMA Negeri 1 Kota Bengkulu. Nilai rata-rata UN matematika dan IPA SMAN 1 Kota Bengkulu di tahun 2017 hanya 42,605. Tentu saja nilai ini jauh dari yang diharapkan, ditambah lagi nilai UN matematika ini merupakan nilai terkecil di antara nilai mata pelajaran yang lain di SMAN 1 Kota Bengkulu (Tim Dapodikbud, 2017).

Berdasarkan perbincangan dengan guru di SMA N 1 Kota Bengkulu, penyebab rendahnya kemampuan pemahaman dan pemecahan masalah matematika dan IPA siswa diantaranya adalah pola pembelajaran masih berlangsung secara konvensional. Pembelajaran masih berpusat pada guru, dalam hal ini gurulah yang aktif menjelaskan materi, sementara siswa pasif. Terkadang guru tidak mampu membuat siswa mengerti apa yang sedang dipelajari, komunikasi berlangsung satu arah, guru memberikan materi, dan siswa menerima. Metode ini diberikan hampir setiap hari sehingga membuat siswa kesulitan memahami matematika dan IPA. Sudah terbiasa mengajar secara konvensional, dan lebih praktis menjadi alasan mengapa mereka susah untuk berubah. Hanya beberapa guru saja yang terkadang menggunakan komputer sebagai media pembelajaran. Untuk itu diperlukan pelatihan mengenai inovasi pada pembelajaran.

Model Pembelajaran Kalkulus Berdasarkan Teori APOS (MPK-APOS), merupakan model pembelajaran kalkulus yang berpusat pada mahasiswa dengan sitak yang terdiri dari fase: Orientasi, Praktikum, Diskusi Kelompok Kecil, Diskusi Kelas, dan Evaluasi (Hanifah, 2015). Model MPK-APOS sudah dinyatakan valid, praktis dan efektif, dan dapat meningkatkan hasil belajar mahasiswa, dapat meningkatkan keaktifan mahasiswa, dapat meningkatkan motivasi mahasiswa, dan mendapat respon yang positif dari mahasiswa. Istilah MPK-APOS dikembangkan atau diperluas lagi untuk seluruh materi matematika menjadi Model Pembelajaran Matematika berdasarkan teori APOS (Model APOS) (Hanifah, 2016). Implementasi Model APOS ini telah dilakukan pada mahasiswa pendidikan matematika dan mahasiswa teknik informatika untuk mata kuliah Kalkulus Integral dan Geometri Transformasi (Hanifah, 2017; Hanifah \& Irsal, 2017; Hanifah, 2018; Hanifah \& Irsal 2018). Gambar 1 menunjukkan bagan Model APOS beserta komponenkomponennya. 


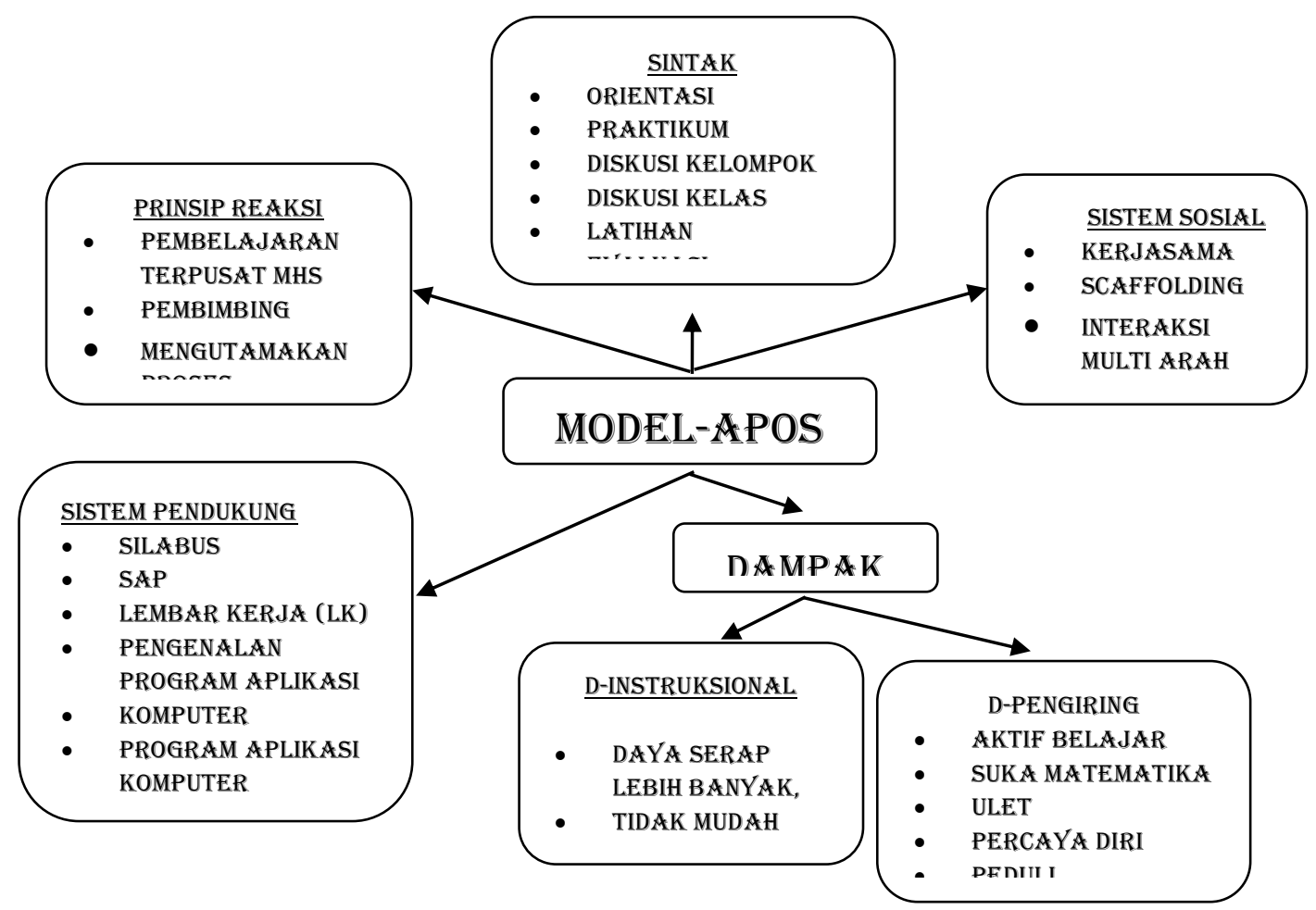

Gambar 1. Model Pembelajaran Matematika Berdasarkan Teori APOS (Hanifah, 2016)

APOS merupakan suatu teori pembelajaran yang dapat digunakan untuk pembelajaran matematika terpusat pada siswa, yang mengintegrasikan penggunaan komputer, belajar dalam kelompok kecil, dan memperhatikan konstruksi-konstruksi mental siswa dalam memahami suatu konsep matematika. Konstruksi-konstruksi mental tersebut adalah: aksi (action), proses (process), objek (object), dan skema (schema) yang disingkat dengan APOS (Dubinsky, 2001; Arnawa, 2006; Arnawa, 2009; Suryadi, 2010).

Model APOS semula ditujukan untuk pembelajaran matematika di perguruan tinggi. Sintaks Model APOS yang bersesuaian dengan pendekatan saintifik, serta adanya peraturan pemerintah yang mengharuskan diterapkannya kurikulum K-13, yang mendorong pembelajaran terpusat pada peserta didik (Kemdikbud, 2013), maka dikembangkanlah LKPD berbasis Model APOS dengan pendekatan Saintifik. Pembelajaran dengan pendekatan saintifik adalah proses pembelajaran yang dirancang sedemikian rupa agar peserta didik secara aktif mengkonstruksi konsep, hukum, atau prinsip melalui tahapan-tahapan mengamati (untuk mengidentifikasi atau menemukan masalah), merumuskan masalah, mengajukan atau merumuskan hipotesis, mengumpulkan data dengan berbagai teknik, menganalisa data, menarik kesimpulan dan mengkomunikasikan konsep, hukum atau prinsip yang "ditemukan" (Daryanto, 2014).

Pertama kali LKPD berbasis Model APOS dengan pendekatan saintifik dan berbantuan Geogebra dibuat oleh guru-guru matematika yang menjadi mahasiswa program studi S2 Pendidikan Matematika FKIP UNIB TA 2017/2018, yang mengikuti matakuliah Geometri. Guru-guru tersebut memberikan respon yang positif terhadap Lembar Kerja berbasis Model APOS dengan pendekatan Saintifik dan berbantuan Geogebra. Diantara guru tersebut bahkan ada yang berhasil mencoba menerapkannya di sekolah. 
Guru matematika dan IPA SMAN 1 Kota bengkulu belum mengenal Model APOS dalam pembelajaran matematika dengan pendekatan saintifik dan berbantuan komputer. Untuk itu kami memandang perlu untuk mengadakan pengabdian pada masyarakat dengan judul kegiatan Pelatihan Pengembangan Perangkat Pembalajaran Geometri Berbasis Model APOS Berbantuan Komputer dengan Pendekatan Saintifik kepada guru-guru Matematika dan IPA SMAN 1 Kota Bengkulu. Harapan kami, dengan kegiatan pengabdian ini, guru-guru MIPA di SMAN 1 Kota Bengkulu dapat membuat sendiri LKPD berbasis Model APOS dengan pendekatan saintifik, yang mendapat respon positif dari siswa ketika menerapkan LKPD tersebut di kelas, sebagai upaya meningkatkan keterampilan dan pemahaman siswa ke depannya.

\section{METODE PENGABDIAN}

Pengabdian dilaksanakan pada tanggal 07 s.d 3 Oktober 2018 di SMA Negeri 1 Kota Bengkulu. Pelatihan pembuatan LKPD Model APOS dengan pendekatan saintifik berbantuan komputer dilakukan kepada 23 orang guru matematika dan IPA. Setelah guru berhasil membuat LKPD, 31 siswa kelas XII IPA 1 menjadi peserta implementasi untuk melihat respon mereka terhadap LKPD Model APOS dengan pendekatan saintifik berbantuan komputer. Pelaksanaan pengabdian ini dilakukan dengan beberapa tahapan berikut.

1. Pengenalan LKPD Model APOS dengan pendekatan saintifik berbantuan komputer.

Tahapan pertama ini dilakukan dengan metode simulasi. Guru-guru diberikan contoh LKPD yang sudah jadi, dan diminta mengerjakannya seolah mereka menjadi siswa. Dengan demikian guru mengalami langsung proses mental mulai dari aksi (action), proses (process), objek (object), sampai membentuk skema (schema) dalam pembelajaran. Akhirnya guru dapat lebih paham bagaimana merancang LKPD Model APOS dengan pendekatan saintifik berbantuan komputer.

2. Perancangan LKPD oleh kelompok guru

Guru-guru diberi kesempatan selama dua mingu untuk merancang LKPD Model APOS dengan pendekatan saintifik berbantuan komputer secara berkelompok, sesuai dengan mata pelajaran yang diampu. Dalam rentang waktu ini, pembinaan dan pendampingan dilakukan dalam bentuk diskusi, baik tatap muka, maupun via media komunikasi daring.

3. Presentasi LKPD

Rancangan LKPD yang telah dibuat kelompok guru dipresentasikan dan didiskusikan bersama mentor dan seluruh guru peserta pelatihan.

4. Implementasi LKPD

Implementasi LKPD terpilih dilaksanakan pada tanggal 2 okober 2018 pada kelas XII IPA 1. Untuk mengamati respon siswa.

\section{HASIL DAN PEMBAHASAN}

Pelatihan yang diberikan pada kegiatan pengabdian ini mendapat respon positif dari guru Matematika dan IPA SMAN 1 Kota Bengkulu sebagai peserta pelatihan. Peserta yang semula belum mengenal model APOS sangat antusias mengikuti pelatihan pembuatan LKPD ini. Kegiatan pengenalan dilakukan dengan simulasi pembelajaran matematika SMA pada materi persamaan lingkaran dengan menggunakan contoh LKPD berbasis Model APOS dengan pendekatan Saintifik berbantuan Geogebra yang diberikan pemateri. Guru-guru peserta pelatihan berperan sebagai siswa SMA dan mencoba mempelajari 
materi lingkaran dengan mengerjakan setiap tahapan LKPD tersebut. Bahkan guru-guru IPA yang belum mengenal Geogebra pun sangat antusias mempelajarinya. Pada tahap diskusi kelas, guru-guru IPA yang diminta mempresentasikan hasil pengerjaan LKPD materi lingkaran dapat menyelesaikannya dengan baik. Gambar 2 Menunjukkan salah satu guru kimia dan fisika yang melakukan presentasi. Setelah simulasi model APOS tersebut, guru-guru diberi kesempatan tanya jawab dengan pemateri terkait perancangan LKPD yang akan dilakukan.
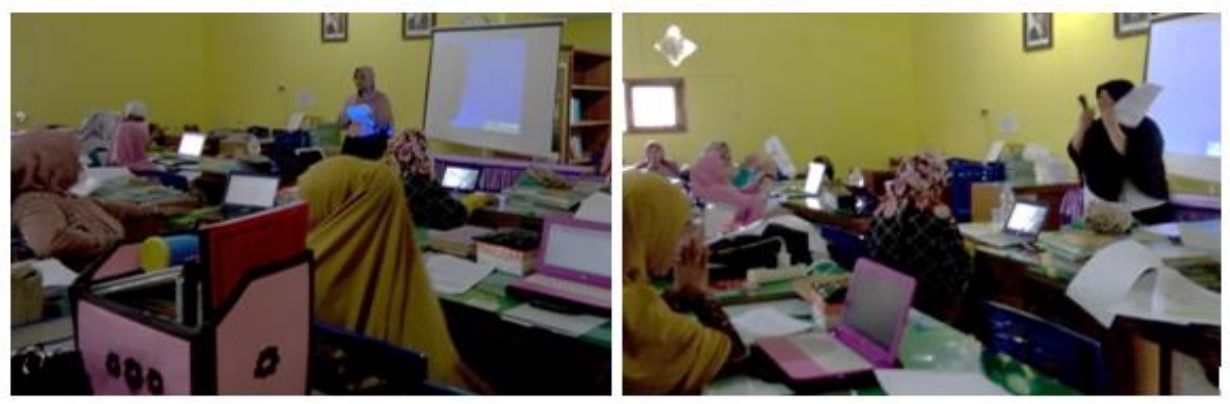

Gambar 2. Presentasi dan tanya jawab dengan pemateri terkait perancangan LKPD

Tahap selanjutnya guru-guru merancang LKPD berbasis Model APOS dengan pendekatan Saintifik berbantuan Geogebra, sesuai dengan kelompok mata pelajaran masing-masing. Guru fisika mencoba merancang LKPD untuk materi vektor gaya, guru kimia mencoba merancang untuk materi laju titrasi. Guru matematika merancang LKPD materi dilatasi.

Setelah dua minggu waktu perancangan, guru-guru berkumpul kembali untuk mempresentasikan hasil rancangan LKPD berbasis Model APOS dengan pendekatan Saintifik berbantuan Geogebra. Ternyata guru mengalami kesulitan untuk merancang LKPD bila program aplikasi yang harus dipakai adalah Geogebra. Tidak semua materi bisa dibuat LKPDnya berbantuan Geogebra, terlebih untuk pelajaran IPA. Untuk mengatasi hal tersebut kami sepakat bahwa rancangan LKPD berbasis Model APOS dengan pendekatan saintifik berbantuan komputer. Program aplikasi komputer yang dipilih boleh yang lain, misalnya Ms.Excel.

Kelompok guru Matematika berhasil membuat LKPD berbasis Model APOS dengan pendekatan Saintifik berbantuan Geogebra untuk pokok bahasan dilatasi dan statistika. Namun sayangnya materi Dilatasi masih lama jadwalnya. Materi yang sesuai jadwal adalah Statitika, sehingga guru kelompok matematika hanya mengujicoba LKPD Statistik Berbasis Model APOS dengan pendekatan Saintifik berbantuan Ms.Excel. LKPD Statitik tersebut diujicobakan di kelas XII IPA 1 SMA N 1 Kota Bengkulu. Berikut ini adalah contoh isi LKPD Statistik untuk setiap fase dari sitak Model APOS. 


\section{a. Fase Orientasi}

Tujuan Pembelajaran :

1. Siswa dapat menentukan ragam dan simpangan baku suatu data berkelompok yang disajikan dalam distribusi frekuensi.

2. Siswa dapat menentukan ragam dan simpangan baku suatu data berkelompok yang disajikan dalam histogram.

Materi Prasyarat :

Rata-Rata data berkelompok

Menanya :

Gambar 3. Contoh Isi LKPD Statistik Fase Orientasi

\section{b. Fase Praktikum ((Mengeksplorasi dan Mengamati)}

Menemukan Rumus Ragam dan Simpangan Baku menggunakan Microsoft excel

Ikuti prosedur berikut....

1) Buka sheet "Distribusi Frekuensi", Lengkapilah table distribusi berikut

\begin{tabular}{|c|c|c|c|c|c|c||}
\hline \multicolumn{7}{|c|}{ Simpangan Baku dan Ragam } \\
\hline \hline No & Kelas & Frekuensi & Titik Tengah & fi $\cdot \mathrm{xi}$ & $\mathrm{xi}{ }^{\wedge} 2$ & fi $\cdot \mathrm{xi}^{\wedge} 2$ \\
\hline \hline 1 & $8-12,0$ & 2 & & & & \\
\hline 2 & $13-17$ & 8 & & & & \\
\hline 3 & $18-22$ & 15 & & & & \\
\hline 4 & $23-27$ & 7 & & & & \\
\hline 5 & $28-32$ & 10 & & & & \\
\hline
\end{tabular}

Gambar 4. Contoh Isi LKPD Statistik Fase Praktikum

\section{c. Fase Diskusi Kelompok Kecil (Mengasosiasi)}

Analisislah hasil yang kamu temukan dari keempat rumus tersebut? Jawablah pertanyaan yang anda ajukan pada fase orientasi sebelumnya. Diskusikan ukuran penyebaran data berkelompok yang anda dapatkan dengan teman sebangku anda. Diskusikan pula hasilnya dengan teman sekelas anda untuk mendapatkan kesimpulan kelas. Diskusi dan berpendapat yang santun untuk mendapatkan hasil yang maksimal. Tuliskan kesimpulan anda pada kotak di bawah ini.

Gambar 5. Contoh Isi LKPD Statistik Fase Diskusi kelompok Kecil 


\section{d. Fase Diskusi Kelas (Mengkomunikasikan dan Menanya)}

Presentasikan hasil diskusi kelompokmu di depan kelas. Buatlah pertanyaan mengenai ragam dan simpangan baku, kemudian pertanyaan tersebut untuk didiskusikan dengan kelompok lain dalam diskusi kelas.

Tulis kesimpulan yang kamu peroleh.

\section{Gambar 6. Contoh Isi LKPD Statistik Fase Diskusi Kelas}

\section{e. Fase Latihan/Evaluasi}

Tugas Individu, kerjakan pada buku latihan masing-masing)

Tiga puluh sepeda motor terpilih dites untuk mengetahui efisiensi bahan bakar

dalam kilometer per liter. Distribusi frekuensi yang didapatkan disajikan berikut ini.

\begin{tabular}{|c|c|c|}
\hline No & Kelas & Frekuensi \\
\hline 1 & $8-12,0$ & 2 \\
\hline 2 & $13-17$ & 8 \\
\hline 3 & $18-22$ & 15 \\
\hline 4 & $23-27$ & 7 \\
\hline 5 & $28-32$ & 10 \\
\hline \multicolumn{2}{|c|}{ Jumlah } & \\
\hline
\end{tabular}

Gambar 7. Contoh Isi LKPD Statistik Fase Latihan

\section{f. Hasil Uji Coba LKPD di Kelas XII IPA 1}

\section{1) Hasil LKPD dan Pengamatan}

LKPD yang telah dibuat oleh kelompok guru matematika tersebut, pada tanggal 2 Oktober diujicobakan di kelas XII IPA 1 SMA N 1 Kota Bengkulu dengan jumlah siswa 31 orang. Sebelum pembelajaran dimulai, siswa sudah dibagi ke dalam kelompok kecil yang heterogen kemampuannya yang terdiri dari 3-4 orang siswa. Secara umum berdasarkan pengamatan dan penilaian oleh guru, kemampuan siswa di kelas tersebut terbagi tiga yaitu: $8(25,81 \%)$ siswa berkemampuan tinggi, $18(58,06 \%)$ siswa berkemampuan sedang, dan 5 siswa $(16,13 \%)$ berkemampuan rendah. Masing-masing kelompok membawa satu Laptop.

Berdasarkan informasi dari guru: a) Hasil LKPD setelah diujicobkan di kelas, kemudian dikumpul dan diperiksa. Hasilnya semua kegiatan/perintah pada LKPD dijawab oleh semua kelompok dan nilainya bagus- bagus. b) Hasil pengamatan selama pembelajaran berlangsung anak-anak terlihat lebih aktif dan antusia dalam belajar. Fotofoto berikut sebagai bukti keaktifan siswa selama pembelajaran berlangsung 

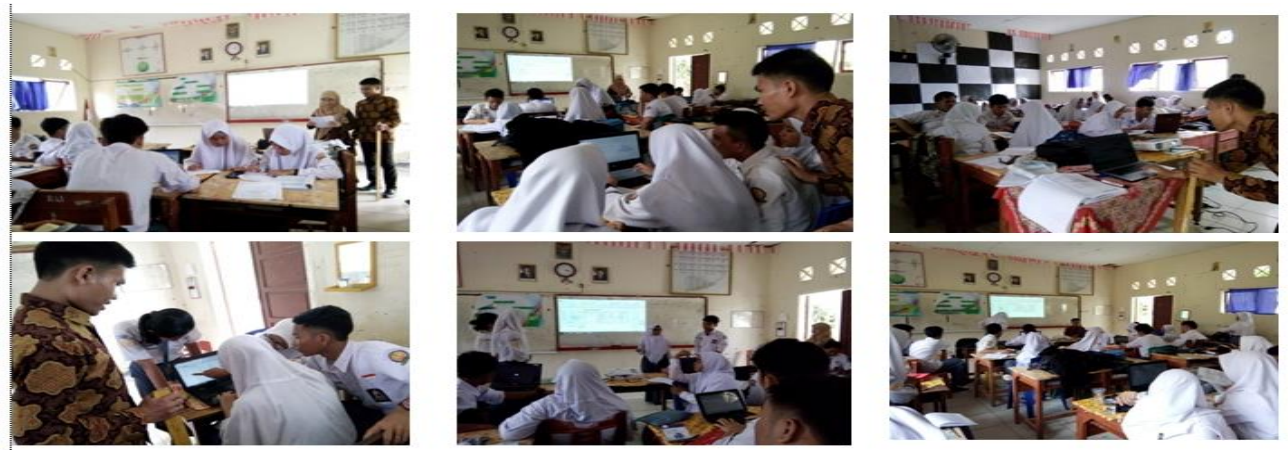

Gambar 8. Foto Ujicoba LKPD Statistik

\section{2) Hasil Olah Angket Terbuka}

Untuk mengetahui respon siswa, maka diberikan angket terbuka pada siswa. Jumlah siswa yang mengembalikan angket 31 siswa.

Pertanyaan 1. Apakah anda suka belajar menggunakan lembar kerja APOS berbantuan

\section{komputer? Berikan alasannya}

Jawab:

- Ada 21 orang ( 67,74\%) yang menjawab suka

- Alasannya diantaranya adalah: Dapat menambah ilmu kami dan kalimatnya lebih jelas, Kami lebih mudah memahami pelajarannya; Lebih mudah memahami pakai komputer kerjanya lebih cepat; Memudahkan menghitungnya; Cepat menyelesaikannya; Kita telah hidup diera globalisasi jadi harus bisa menggunakan teknologi salah satunya komputer lebih mempermudah; Tidak mencatat; Menmbah ilmu pengetahuan dan lebih mudah pengerjaannya; Dengan belajar dari koputer itu sangat membantu. Kami jadi terbiasa dan berpengalaman dalam hal itu. Komputer dijaman sekarang sangat dibutuhkan . kerja dimanapun komputer dibutuhkan

- Ada $=10$ orang $(32,26 \%)$ yang menjawab tidak suka

- Alasannya dirangkum sebagai barikut. Saya agak sedikit kurang mengerti komputer; Terlalu ribet untuk memasukkannya ke dalam komputer; Saya kurang memahami excel, saya lebih suka manual; Susah dipahami karena ada yang mengerjakan di LK, jadi tidak paham yang dikomputer dan sebaliknyamenurut saya jadi repot; Yang memakai komputer cuman satu orang

\section{Pertanyaan 2. Apakah anda suka belajar dalam kelompok? Berikan alasannya}

Jawab

- Ada 24 orang $(77,42 \%)$ yang menjawab suka

- Alasanya dirangkum sebagai berikut. Belajar berkelompok bisa saling berdiskusi pendapat dan bisa bertukar pikiran supaya lebih paham dan dapat memperbaiki kesalahan; Memperluas pengetahuan; Kalau tidak mengerti bisa menanyakan kepada teman sekelompok; Belajar berkelompok itu menyenangkan bisa bertukar pikiran; Kami mudah mengerti karena berdiskusi dan bisa memberi pertanyaan kepada teman yang sudah paham; Bisa saling berbagi ilmu dan semua soal bisa dikerjakan dengan cepat; Didalam kelompok akan melakukan diskusi dan melihat jawaban yang paling benar, teman yang bisa menjawab harus membantu teman yang kurang bisa; Bisa berbagi pendapat bersama menciptakan suat kebersamaan dalam menyelesaikan suatu masalah

- Ada 7 orang $(22,58 \%)$ yang menyatakan tidak suka 
- Alasannya dirangkum sebagai berikut. Terkadang didalam kelompok ada orang yang tidak ingin bersosialisasi; Saya menyukai belajar individu; Saya tidak suka berkelompok dengan urang yang tidak sepaham dengan saya; Kurang memahami, lebih baik dijelaskan langsung oleh guru

\section{Pertanyaan 3. Apa anda bisa mengerti tentang materi yang ada pada lembar kerja? Berikan alasannya}

Jawab

- $\quad$ Ada 26 orang ( $83,87 \%$ ) yang menjawab mengerti

- Alasan yang diberikan dirangkum sebagai berikut. Sudah diberi panduan dibagian atas lembar kerja; Saya memakluminya sebelum saya melihat lembar kerja; Lebih mudah dipahami dan dikerjakan; Lebih informatif jadi bisa memahami; Guru memberikan cara /jalan agar bisa mendapatkan hasil; Kami lebih mengerti pemahaman dengan materi lembar kerja; Mengisi bersama teman-teman kelompok; Materi yang disampaikan menantang membuat bersemangat sehingga materi itu mudah dipahami, dan juga guru yang mengajar mengajarkan sangat baik; Jika sudah dijelaskan atau dipresentasikan mudah dipahami

- Ada 5 Orang ( $16,13 \%$ ) yang menyatakan mengerti materi yang diajarkan

- Alasannya dirangkum sebagai berikut. Ada materi yang susah dipahami; Soal contoh dengan soal yang diberikan caranya beda; Kadang tidak mengerti; Kadang membingungkan karena materi terlalu rumit; Ada beberapa kelompok materi yang saya kurang mengerti

Pertanyaan 4. Untuk yang bisa mengerti materi, pada fase mana anda sudah mengerti (Pilih

fase: Praktikum, Diskusi Kelompok Kecil, Presentasi atau Latihan). Berikan alasannya

Jawab

- $\quad$ Yang sudah mengerti pada fase Praktikum ada 11 orang ( $35,48 \%$ )

- Alasannya dirangkaum sebagai berikut. Saya lebih suka praktikum; Pada praktikum kita diuji dengan baik; Lebih mudah penggunaannya; Lebih mudah dipahami; Kita bisa mengerjakannya langsung; Kalau salah bsa diulang lagi

- Yang sudah mengerti pada fase Diskusi Kelompok Kecil ada = 18 siswa $(58,06 \%)$

- Alasannya dirangkum sebagai berikut: Saya bisa bertanya pada teman saya yang lebih menguasai materi; Bisa fokus dalam pembelajaran; Bersama kelompok bisa mengerjakan atau materi lebih mudah; Bisa saling berbagi ilmu dengan teman kelompok dan saling mengajari; Bisa bertukar pendapat dengan teman lain dan juga awalnya kami tidak paham dengan diskusi kami menjadi paham; Bisa mendapatkan pendapat dari teman dan lebih mengerti jika teman menjelaskan karena wajahnya nyaman, penjelasannya menarik.

Yang sudah mengerti pada fase Diskusi Kelas ada 0 orang ( $0 \%$ ). Ada seorang siswa yang berkomentar,

- Tidak ada siswa yang mengatakan baru mengerti pada fase Diskusi Kelas, tetapi ada yang memberikan jawaban berikut. Saya suka mempresentasikan jawaban

- Yang sudah mengerti pada fase Latihan ada = 2 siswa $(7,69 \%)$

- Alasannya; Karena menguji kemampuan dari diri dari yang sudah diterangkan; Lebih jelas untuk memahaminya 
Beberapa saran yang sifatnya membangun tentang Model APOS yang diberikan oleh siswa adalah: perbanyak siswa maju ke depan agar semua mendapat ilmu; Lebih sering kerja kelompok; Lebih banyak belajar menggunakan lembar kerja berbantuan komputer.

\section{PEMBAHASAN}

Pelatihan yang diberikan menghasilkan respon positif dan pemahaman guru matematika dan IPA SMAN 1 Kota bengkulu. Respon dan pemahaman ini membuat guruguru pesaerta pelatihan mampu membuat lembar kerja berbasis model APOS dengan pendekatan saintifik berbantuan komputer.

Hasil pelaksannaan ujicoba lembar kerja berbasis model APOS berbantuan komputer dengan pendekatan saintifik mendapat mayoritas respon positif dari siswa, bahkan siswa sudah bisa merasakan dampak positifnya, yaitu rasa senang dalam belajar, cepat mengerti, bisa saling bertukar pendapat dengan teman, bisa bertanya pada teman, dan bisa mengajari teman. Hal ini sesuai dengan pernyatan Slavin, bahwa inti dari pembelajaran kooperatif (Slavin, 2005), dalam metode pembelajaran kooperatif, para siswa akan duduk bersama dalam kelompok yang beranggotakan empat orang untuk menguasai materi yang akan dipelajari.

Berdasarkan jawaban pertanyaan nomor 3 tentang pada fase apa siswa baru mengerti materi, terlihat bahwa jawaban terbanyak ada pada fase diskusi kelompok kecil jumlanya $=$ $58,06 \%$. Hal ini terjadi karena adanya saling berbagi pendapat diantara anggota kelompok kecil. Scaffolding juga diberikan guru kepada kelompok yang mengalami kesulitan pada tahap ini.

Hal ini memperlihatkan bahwa sudah terjalin komunikasi multiarah dari siswa ke guru dan dari siswa ke siswa. Komunikasi ini dalam rangka pemberian bantuan oleh guru pada siswa atau oleh siswa ke siswa. Hal ini sesuai dengan pendapat Slavin berikut ini:

"Cooperative learning comprises "instructional methods in which teachers organize students into small groups, which then work together to help one another learn academic content". Cooperative learning consists of five basic elements: positive interdependence, promotive interaction, individual accountability, teaching of interpersonal and social skills, and quality of group processing. Learning situations are not cooperative if students are arranged into groups without positive interdependence (Johnson \& Johnson). Positive interdependence means that in cooperative learning situations, students are required to work together as a cohesive group to achieve shared learning objectives (Yager). In the process, students must be responsible for the other group members' learning" (Slavin) in (Tran, Van Dat, 2014).

Yunus Abidin (2016) mengatakan bahwa pembelajaran mengandung dua karakteristik utama yakni, (1) proses pembelajaran melibatkan proses mental siswa secara maksimal yang menghendak aktivitas siswa untuk berfikir dan (2) pembelajaran diarahkan untuk memperbaiki dan meningkatkan kemampuan berfikir siswa yang pada gilirannya kegiatan berfikir itu dapat membantu siswa untuk memperoleh pengetahuan yang mereka konstruksi sendiri. Berdasarkan kedua karakteristik ini jelas pembelajaran bukan hanya dilakukan sebagai transfer pengetahuan melainkan kegiatan yang harus dilakukan secara aktif beraktivitas dalam upaya membangun pengetahuannya sendiri berdasarkan potensi yang telah dimilikinya.

Menurut Vygotsky, belajar dapat membangkitkan berbagai proses mental tersimpan yang hanya bisa dioperasikan manakala seseorang berinteraksi dengan orang dewasa atau berkolaborasi dengan sesama teman. Melalui interaksi antar siswa, diharapkan terjadi 
pertukaran pengalaman belajar yang berbeda dimana siswa yang lebih dahulu menguasai materi dapat membantu temannya yang lambat darinya, sehingga aksi mental dapat terus berlanjut sesuai dengan yang diharapkan (Suryadi, 2011).

Berdasarkan jawaban siswa pada pertanyaan nomor 3 terlihat bahwa masih ada $16,13 \%$ yang tidak mengerti materi. Kemungkinan siswa-siswa ini gagal berintegrasi dengan teman kelompoknya. Vygotsky mengemukakan tiga kategori pencapaian siswa dalam upayanya memecahkan permasalahan, yaitu (1) siswa mencapai keberhasilan dengan baik, (2) siswa mencapai keberhasilan dengan bantuan, (3) siswa gagal dalam meraih keberhasilan. Scaffolding, berarti upaya pembelajar untuk membimbing siswa dalam upayanya mencapai keberhasilan. Dorongan guru sangat dibutuhkan agar pencapaian siswa ke jenjang lebih tinggi menjadi optimum (Ratumanan, 2004).

\section{KESIMPULAN DAN SARAN}

\section{Kesimpulan}

Indikator keberhasilan dari kegiatan pengabdian pada masyarakat ini adalah adanya LKPD berbasis Model APOS dan berbantuan komputer buatan kelompok guru matematika dan IPA. Kelompok guru matematika berhasil membuat LKPD Dilatasi berbantuan Geogebra, dan LKPD Statistik berbantuan MS Excel. LKPD yang bisa diterapkan mengikuti jadwal pelajaran adalah LKPD Statistik. Setelah LKPD Statistik diujicobakan di kelas XII IPA 1 SMA N 1 Kota Bengkulu yang diikuti oleh 31 siswa, diperoleh hasil sebagai berikut: 67,74 \% siswa suka belajar menggunakan LKPD berbasis Model APOS dengan pendekatan Saintifik berbantuan MS Excel; 77,42 \% siswa suka belajar berkelompok; 83,87 \% mengerti materi. Berdasarkan hasil pengamatan, siswa terlihat antusias dan aktif selama pembelajaran berlangsung. Dapat disimpulkan bahwa Model APOS dengan pendekatan Saintifik Berbantuan Komputer mendapat respon yang positif siswa. Siswa bisa merasakan dampak positif dari pembelajaran menggunakan Model APOS yaitu bisa saling bertanya atau saling memberi tanggapan serta terjadi scaffolding guru kepada siswa.

\section{Saran}

Berdasarkan antusias dan respon siswa, serta dampak positif yang dirasakan oleh siswa dengan diterapkannya Model APOS dengan pendekatan Saintifik, dan berbantuan Komputer, maka diharapkan para guru matematika mau menerapkan Model APOS. Program aplikasi yang dipakai tidak harus GeoGebra atau MS Excel, tetapi pakailah yang cocok untuk materi yang sedang dipelajari. Untuk kegiatan pengabdian selanjutnya, perlu difokuskan pelatihan penggunaan program komputer sebagai penunjang penerapan Model APOS dengan pendekatan saintifik.

\section{DAFTAR PUSTAKA}

Arnawa, 2006, Meningkatkan Kemampuan Pembuktian Mahasiswa dalam Aljabar Abstrak Melalui Pembelajaran Berdasarkan Teori APOS, Disertasi pada Universitas Pendidikan Indonesia, Tidak diterbitkan.

Arnawa, 2009, Mengembangkan Kemampuan Mahasiswa dalam memvalidasi Bukti pada Aljabar Abstrak melalui Pembelajaran Berdasarka Teori APOS, Padang: FMIPA,UNAND. 
Daryanto, 2014, Pendekatan Pembelajaran Saintifik Kurikulum 2013, Yogyakarta, Gava Media.

Dubinsky, 2001, Using a Theory of Learning in College Mathematics Courses, Coventry: University of Warwick http://mathstore.ac.uk/newsletter/may2001/pdf/learning.pdf

Hanifah, 2015, Pengembangan Model Pembelajaran Kalkulus Berdasarkan Teori APOS. Disertasi. Program Pascasarjana UNP. Tidak dipublikasikan.

Hanifah, 2015, Developing Calculus Learning Model Based On The Theory of APOS (Action, Process, Object, And Schema), Proceeding, ISBN: 978-602-19877-3-5. The International Conference On Mathematics, Science, Education And Technologi.. October 22, 2015, Inna Muara Hotel and Convention Center, Padang Indonesia. Hal. $76-85$.

Hanifah, 2016, Model APOS. Inovasi Pada Pembelajaran Matematika. Bengkulu. FKIP UNIB Press.

Hanifah, 2016, Development of math worksheets bases on APOS model ( a case study of Integral Calculus), Proceeding, ISBN: 978-602-19877-5-9. The Fourth South East Asia Design/Development Research International Conference 2016, Graduate Programme, Uninersitas Negeri Padang. April, $17^{\text {th }}-18^{\text {th }} 2016$. Hal. $142-156$.

Hanifah, 2016, Kepraktisan Lembar Kerja Berbasis Model Pembelajaran Kalkulus Berdasarkan Teori APOS, Prosiding ISBN: 979-602-71798-1-3 Semirata 2016 Bidang MIPA BKS-PTN Wilayah Barat. Graha Sriwijaya, Universitas Sriwijaya Palembang, 22-24 Mei 2016. Hal 214 - 224.

Hanifah, 2016, Peranan Komputer Pada Model Pembelajaran Matematika Berdasarkan Teori APOS (Model APOS), Prosiding ISSN: 2580 - 1104. Seminar Nasional Matematika V Universitas Negeri Jakarta 5 November 2016, Hal. 13-16

Hanifah, 2016, The Impact of Mathematics Learning Model Implementation Based on APOS Theory (APOS Model), (A Case Study on Integral Calculus Learning), International Conference on Science and Technology, "science and technology for improving quality of life", November 9-10, 2016, Pekanbaru, Indonesia, http://www.estech.org. Hal $573-579$.

Hanifah, 2017, Kepraktisan Lembar Kerja Berbasis Model Pembelajaran Matematika Berdasarkan Teoari APOS (Model APOS) oleh Mahasiswa Teknik Informatika Fakultas Teknik UNIB TA 2015/2016 (Studi Kasus Pada Pembelajaran Kalkulus); Prosiding SEMIRATA 2017 Bidang MIPA BKS-PTN Wilayah Barat. Jambi. Ratu Convention Center 12 - 14 Mei 2017, Hal. 723 - 725.

Hanifah., Irsal,N, A., 2017, The Implementation of APOS MODEL In Transformation Geometry Course, Proceeding of International Conference on Mathematics and Mathematics Education) ICM2E) 2017, ISBN: 978-602-50919-0-2, Novotel Hotel Bukittinggi 27 - 29 August 2017 hal. 89 - 95.

Hanifah, 2017, Computer Based APOS Model on Mathematics Learning, Proceeding ISBN: 2598-2532, International Conference of Applied Science on Engineering, Business, Linguistics and Information Technology (Ico-ASCNITech), Politeknik Negeri Padang and Politeknik Ibrahim Sultan, 13 -15 October 2017, Hal. 16 - 22.

Hanifah., Irsal,N, A., 2017, Collage Students' Errors in Solving Volume of Solids of Revolution Problems and the Scaffolding Given on Model APOS Learning, Proceeding ISBN : 978-602-8043-84-7, Bengkulu International Conference (BICSE-2017). Rectorate Building $3^{\text {rd }}$ Floor, University of bengkulu. December $14-$ 15, 2017, Hal. 100 -107. 
Hanifah, 2017, Implementasi Model APOS pada matakuliah Kalkulus Integral pada pokok Bahasan Fungsi Transenden di Prodi Pendidikan Matematika FKIP UNIB TA 2017/2018, Prosiding ISBN: 978-602-8043-83-0, Conference on Mathematics, Science, and Education, Gedung Dekanat FKIP UNIB 21-23 Desember 2017, hal $230-238$.

Hanifah., Irsal, N., A, 2018, The Impact of Calculus Learning Based on APOS MODEL to Students' Mastery of Improper Integral Materials, Paper presented at Semirata and International Conference on Science and Technology (SEMIRATA -ICST) 2018, Medan International Convention Center (MICC) May 4 -6th, 2018

Hanifah., Irsal,N, A, 2018, The Effectivity of APOS Model Based Worksheets On The Improper Integral, Paper presented at International Conference on Mathematics, Science, Education and Technology (ICOMSET) 2018, At Universitas Negeri Padang, Padang City, Indonesia, On October $4-5^{\text {th }}$.

Hanifah, 2018, Membangun Karakter Kritis, Ulet, Dan Percaya Diri Melalui Penerapan Model APOS (Studi Kasus Pada Pembelajaran Kalkulus Integral), Makalah yang telah diseminarkan pada tanggal 25 Oktober 2018 pada ICETeP. FKIP UNIB

Kemdikbud, 2013, Pengembangan Kurikulum 2013, Paparan mendikbud dalam Sosialisasi Kurikulum 2013, Jakarta: Kemdikbud.

Ratumanan,2004, Belajar dan Pembelajaran, UNESA University Press, Surabaya.

Slavin, 2005, Cooperatove Learning Teori, Riset dan Praktek, Bandung Nusa Media.

Suryadi, 2010, Menciptakan Proses Belajar Aktif: Kajian Dari Sudut Pandang Teori Belajar Dan Teori Didaktikl. Makalah disajikan pada Seminar Nasional Pendidikan Matematika di UNP, 9 Oktober 2010 http://didi-suryadi.staf.upi. edu/files/2011/06/ MENCIPTAKAN-PROSES-BELAJAR-AKTIF.pdf

Suryadi, 2011, Membangun Budaya Baru dalam Berpikir Matematika. Sekolah Pascasarjan Universitas Pendidikan Indonesia; http://www.scribd.com/ doc/93456342/Membangun-Budaya-Baru Dalam-Berpikir diakses pada tanggal 23 Maret 2015.

Tim Dapodikbud, 2017, Sekolah Kita: (10702416) SMAN 1 Bengkulu, http://sekolah.data.kemdikbud.go.id/index.php/chome/profil/967AD80D-958542E8-8388-3C63083345EB\#ujiannasional, diakses Maret 2019.

Tran, Van, Dat, 2014, The Effects of Cooperative Learning on the Academic Achievement and Knowledge Retention, www.sciedu.ca/ijhe, International Journal ofHigher Education, Vol. 3, No. 2; 2014. 